\title{
Impacts of Price Incentives, Costs and Management Awareness on Maize Supply in Two Regions of the USA
}

\author{
Charles McMillan and Xiang Li
}

\begin{abstract}
This study analyzes the impacts of price incentives, costs and management awareness on maize supply in the North Central and the South regions of the United States. Diverting from previous studies, we convert Cobb-Douglas production functions to supply functions in the profit maximizing condition for two regions and use prices and costs to represent the incentives and management indices of farmers in our models. We examine the effects of prices and costs on the decision-making processes of farmers and the corresponding maize supply, where the models simultaneously consider climate and technology improvement elements in addition to price and cost elements. Given the background that climatic and socioeconomic conditions are different in the two regions, analyzing and understanding the regional impact divergence could have significant implications to the United States and the world in the context of securing the stability of the market price and food supply of the crop, as well as adapting to the progress of climate change. We found the South region in the short-term is more responsive to changes in maize prices than the North region, opposite from the results examined in the medium-term scenario and the long-term scenario, reflecting the differences in regional management awareness. While the changes in labor costs and machinery costs in the North region have larger impacts in all scenarios, changes in chemical fertilizer costs have larger impacts in the South region in all scenarios. All in all, further research should be conducted to ensure the stability of the long-term food security.
\end{abstract}

Index Terms-price incentives, costs, management awareness, profit maximizing condition, stability of the market price and food supply, food security.

\section{INTRODUCTION}

Agriculture has been and will continue play its fundamental role in our society. Ensuring a sustainable supply of food under the impact of climate change and socioeconomic changes is critically important to the United States and the world [1]. Farmers, key stakeholders in the agricultural sector, directly influence the result of agricultural production. Thus, analyzing the potential impacts of price incentives, input costs and management awareness on the decision-making process of farmers and the corresponding crop supply would have significant implications to the stability of international crop market price and agricultural supply.

In this study, our focus is maize, one of major crops in the

Manuscript received June 10, 2015; revised October 21, 2015.

Xiang Li is with Chiba University, 263-8522 Japan (e-mail: xiangli22@chiba-u.jp). world. Given the background that the United States is the top producer of maize in the world and its maize export exceeds one-third of the world market share, it is clear the production of maize in this country is important to both the United States and the global economy [1]-[4]. Thus, ensuring a sustainable supply of maize within the country is critically essential.

In the United States, maize is mainly produced in the North Central region, often called the "Corn Belt". Each year, this region produces $50 \%$ of the total amount of maize in the nation [3], [4]. Though the current production level in the South region is much smaller compared to the North Central region and only accounts for $3 \%$ of the total national maize production, its potential for auxiliary production to offset or even to outweigh the climate change-induced maize production loss in the North Central region implies its risk mitigating function in addressing food security and renewable energy issues [3].

While the maize in the North Central region is mainly produced in the six major states (Iowa, Michigan, Minnesota, Wisconsin, South Dakota, and Nebraska) that range from $40^{\circ}$ to $48^{\circ}$ north by latitude, $82^{\circ}$ to $103^{\circ}$ west by longitude, it is mainly produced in the four states in the South region (Texas, Louisiana, Oklahoma, Arkansas) that range from $26^{\circ}$ to $36^{\circ}$ north by latitude, $89^{\circ}$ to $105^{\circ}$ west by longitude [3]. Accordingly, this paper analyzes the responses of farmers to prices and costs in both regions.

Previous studies have tried to use either statistical yield model, biophysical simulation models such as CERES-maize model, DNDC model and EPIC model, or mathematical programming methods to analyze the impacts on maize production [2]-[12]. Diverting from those analyses, we convert adapted Cobb-Douglas production functions to supply functions in the profit maximizing condition for the two regions and use prices and costs to represent the incentives and the management indices of farmers in our models. With the simultaneous incorporation of price variables, input cost variables, climate variables and technology improvement variable in the model, examining the potential impacts of prices and costs on the decision-making processes of farmers and the corresponding maize supply could better approach the real condition.

Stabilizing national crop supply and promoting farmers to continuously produce agricultural products have been challenging topics for all countries. Indeed, analyzing the responses of farmers to changes in price and costs could have significant management and policy implications to the stability of agricultural supply. Our estimated results indicate that the South region in the short-term is more responsive to changes in maize prices than the North region, opposite from the results examined in the medium-term scenario and the 
long-term scenario, reflecting the regional differences in management awareness and induction effects of prices and input costs. While the changes in labor costs and machinery costs in the North region have larger impacts in all scenarios, changes in chemical fertilizer costs have larger impacts in the South region in all scenarios. Such differences imply that different regional agricultural policies rather than a standardized national agricultural policy could be more efficient in addressing food security issues and stabilizing market price and supply of the crop, as well as adapting to the progress of climate change.

\section{MATERIALS AND METHODOLOGY}

For both regions, we convert adapted Cobb-Douglas production function described by $\mathrm{Li}$ and Suzuki [2] to supply function in the profit maximizing condition to analyze the impacts of price incentives, costs and management awareness on maize supply.

The following adapted Cobb-Douglas production function is used

$$
Y=\alpha A^{a} L^{b} M A^{c} C F^{d} e^{i T E C H} e^{e T} e^{-f T^{2}} e^{g P} e^{-h P^{2}}
$$

where $Y$ represents maize production output (bushels), $A$ is land use (in dollars), $L$ is labor that contributes to the production of maize (in dollars), $M A$ represents agricultural machinery use over the process of maize production (in dollars), $C F$ indicates the amount of applied chemical fertilizer (in dollars), TECH represents technology improvement (linear trend term), $T$ and $P$ represent weighted temperature and weighted precipitation where temperature and precipitation in the sensitive planting stage and growing stage of maize (vegetative stage and reproductive stage) are equally weighted separately in the equation (1) (see Table I and Table II) [3].

The adapted Cobb-Douglas production function (1) utilizes time series and cross-sectional data from the six states in the North Central region and the four states in the South region over the time period 1992-2008 and the estimated functions are summarized in Table I [3].

TABLE I: ADAPTED COBB-DOUGLAS PRODUCTION FUnCTIONS IN THE NORTH CENTRAL AND THE SOUTH UNITED STATES [2]

\begin{tabular}{lc}
\hline \hline Region & Adapted Cobb-Douglas production functions \\
\hline North Central & $Y=\alpha A^{0.49} L^{0.32} M A^{0.25} C F^{0.18} e^{0.02 T E C H}$ \\
& $e^{0.27 T} e^{-0.01 T^{2}} e^{0.01 R} e^{\left(-6.89 \cdot 10^{-5)}\right) R^{2}}$ \\
South & $Y=\alpha A^{0.36} L^{0.11} M A^{0.21} C F^{0.35} e^{0.02 T E C H}$ \\
& $e^{0.63 T} e^{-0.01 T^{2}} e^{0.01 R} e^{\left(-3.38 \cdot 10^{-5)}\right) R^{2}}$ \\
\hline \hline
\end{tabular}

TABLE II: SENSITIVE STAGES OF MAIZE CROP AND THE CORRESPONDING TEMPERATURE AND PRECIPITATION IN THE NORTH CENTRAL AND THE SOUTH UNITED STATES [2]

\begin{tabular}{lll}
\hline \hline Stages & North Central & South \\
\hline Planting and seedling & April, May & April, May \\
Growing (Vegetative) & June & June \\
Growing (Reproductive) & July & July \\
\hline \hline
\end{tabular}

Taking the consideration of profit maximization:

$$
\begin{gathered}
\quad \pi=p y-c \\
=p f(A, L, M A, C F, T E C H, T, P)-c(A, L, M A, C F, \\
\left.W_{A}, W_{L}, W_{M A}, W_{C F}\right)
\end{gathered}
$$

where $\pi$ represents profit, $p$ indicates maize price, $p y$ indicates revenue, c represents the total cost, and $W$ represents the corresponding costs of input variables.

Inserting the adapted Cobb-Douglas production function $Y$ to the function (2) where the profit maximization is considered and rewrite the function in the following style

$$
\pi=p \cdot \alpha A^{a} L^{b} M A^{c} C F^{d} e^{i T E C H} e^{e T} e^{-f T^{2}} e^{g P} e^{-h P^{2}}-c
$$

where $c=W_{A} A+W_{L} L+W_{M A} M A+W_{C F} C F$

Considering the condition where the profit maximization is $\pi^{\prime}=0$, input variables $A, L, M A$ and $C F$ are differentiated.

$$
\begin{aligned}
& \frac{\partial y}{\partial A}=p \cdot \alpha a A^{a-1} L^{b} M A^{c} C F^{d} e^{i T E C H} e^{e T} e^{-f T^{2}} e^{g P} e^{-h P^{2}}-W_{A} A=0 \\
& \frac{\partial y}{\partial L}=p \cdot \alpha b A^{a} L^{b-1} M A^{c} C F^{d} e^{i T E C H} e^{e T} e^{-f T^{2}} e^{g P} e^{-h P^{2}}-W_{L} L=0
\end{aligned}
$$

$$
\frac{\partial y}{\partial M A}=p \cdot \alpha c A^{a} L^{b} M A^{c-1} C F^{d} e^{i T E C H} e^{e T} e^{-f T^{2}} e^{g P} e^{-h P^{2}}-W_{M A} M A=0
$$

$\frac{\partial y}{\partial C F}=p \cdot \alpha d A^{a} L^{b} M A^{c} C F^{d-1} e^{i T E C H} e^{e T} e^{-f T^{2}} e^{g P} e^{-h P^{2}}-W_{C F} C F=0$

Equations 4.1 to 4.4 are inserted to the adapted Cobb-Douglas function and a long-term supply function under a completely competitive condition could be obtained.

$$
\begin{gathered}
Y=\alpha a^{a} b^{b} c^{c} d^{d^{\frac{1}{1-(a+b+c+d)}}} W_{A}^{\frac{-a}{1-(a+b+c+d)}} W_{L}^{\frac{-b}{1-(a+b+c+d)}} \\
W_{M A}{ }^{\frac{-c}{1-(a+b+c+d)}} W_{C F}{ }^{\frac{-d}{1-(a+b+c+d)}} p^{\frac{a+b+c+d}{1-(a+b+c+d)}} e^{\frac{i T E C H}{1-(a+b+c+d)}} \\
e^{\frac{e T}{1-(a+b+c+d)}} e^{\frac{-f T^{2}}{1-(a+b+c+d)}} e^{\frac{g P}{1-(a+b+c+d)}} e^{\frac{-h P^{2}}{1-(a+b+c+d)}}
\end{gathered}
$$

For different scenarios (short-term scenario, medium-term scenario and the long-term scenario), land use variable $A$, labor variable that contributes to the production of maize $L$, and the agricultural machinery use variable $M A$ are fixed correspondingly in the equation.

In the short-term scenario, farmers can easily adjust the amount of chemical fertilizer they apply to the maize crop. In terms of labor and agricultural machinery, the alteration of these variables within the short-term could affect the financial performances of farmers and their management processes. Adjustment of these variables becomes easier in a longer time span. Thus, in addition to the applied chemical fertilizer variable, labor variable, as the second variable that could be easily adjusted over the production process of maize, is set to become adjustable in the medium-term scenario. In the long-term scenario, agricultural machinery, labor and applied chemical fertilizer are set to be adjustable.

For the short-term where the land use variable $A$, 
agricultural machinery use variable $M A$, and the labor variable $L$ that contributes to the production of maize are fixed, $A=\bar{A}, M A=\overline{M A}, L=\bar{L}$, the price elasticity of supply $=\frac{d}{1-(d)}$

For the medium-term where the land use variable $A$ and agricultural machinery use variable $M A$ are fixed, $A=\bar{A}, M A=\overline{M A}$, the price elasticity of supply $=\frac{b+d}{1-(b+d)}$

For the long-term where the land use variable $A$ is fixed, $A=\bar{A}$, the price elasticity of supply $=\frac{b+c+d}{1-(b+c+d)}$

\section{RESULTS}

With the processes described above, three patterns of converted supply functions (short-term scenario, medium-term scenario and the long-term scenario) under a completely competitive condition in the North Central and South region could be obtained and the effects of prices and input costs on the decision-making processes of farmers and the corresponding maize supply could be estimated (Table III).

TABLE III: THREE PATTERNS OF CONVERTED SUPPLY FUNCTIONS (SHORT-TERM SCENARIO, MEDIUM-TERM SCENARIO AND THE LONG-TERM SCENARIO) IN THE NORTH CENTRAL AND THE SOUTH REGIONS

\begin{tabular}{|c|c|}
\hline Region, scenario & $\begin{array}{l}\text { Converted supply functions under a completely } \\
\text { competitive condition }\end{array}$ \\
\hline $\begin{array}{l}\text { North Central, } \\
\text { Short-term }\end{array}$ & $\begin{aligned} Y= & \alpha W_{C F}^{-0.22} P^{0.23} e^{0.03 T E C H} \\
& e^{0.33 T} e^{-0.01 T^{2}} e^{0.02 R} e^{\left(-8.41 \cdot 10^{-5)}\right) R^{2}}\end{aligned}$ \\
\hline $\begin{array}{l}\text { North Central, } \\
\text { medium-term }\end{array}$ & $\begin{aligned} Y= & \alpha W_{L}^{-0.64} W_{C F}{ }^{-0.36} P^{1} e^{0.05 T E C H} \\
& e^{0.54 T} e^{-0.02 T^{2}} e^{0.02 R} e^{\left(-3.8 \cdot 10^{-4)}\right) R^{2}}\end{aligned}$ \\
\hline $\begin{array}{l}\text { North Central, } \\
\text { Long-term }\end{array}$ & $\begin{aligned} Y= & \alpha W_{L}^{-1.28} W_{M A}{ }^{-1.01} W_{C F}{ }^{-0.73} P^{3.02} e^{0.1 T E C H} \\
& e^{1.09 T} e^{-0.03 T^{2}} e^{0.05 R} e^{\left(-2.8 \cdot 10^{-4)}\right) R^{2}}\end{aligned}$ \\
\hline South, Short-term & $\begin{aligned} Y= & \alpha W_{C F}{ }^{-0.54} P^{0.54} e^{0.02 T E C H} \\
& e^{0.98 T} e^{-0.02 T^{2}} e^{0.02 R} e^{\left(-5.22 \cdot 10^{-5)}\right) R^{2}}\end{aligned}$ \\
\hline $\begin{array}{l}\text { South, } \\
\text { medium-term }\end{array}$ & $\begin{aligned} Y= & \alpha W_{L}^{-0.21} W_{C F}{ }^{-0.66} P^{0.86} e^{0.03 T E C H} \\
& e^{1.18 T} e^{-0.03 T^{2}} e^{0.02 R} e^{\left(-6.3 \cdot 10^{-5)}\right) R^{2}}\end{aligned}$ \\
\hline $\begin{array}{l}\text { South, } \\
\text { Long-term }\end{array}$ & $\begin{aligned} Y= & \alpha W_{L}^{-0.34} W_{M A}{ }^{-0.66} W_{C F}{ }^{-1.09} P^{2.09} e^{0.05 T E C H} \\
& e^{1.95 T} e^{-0.04 T^{2}} e^{0.03 R} e^{\left(-1.04 \cdot 10^{-4)}\right) R^{2}}\end{aligned}$ \\
\hline
\end{tabular}

For both the North Central and the South of the United States, price elasticity of maize supply in three different time spans are first examined (see Table III and Table IV). In the short-term scenario, land use variable $A$, agricultural machinery use variable $M A$, and the labor variable $L$ that contributes to the production of maize are fixed. Only the applied chemical fertilizer variable $C F$ is allowed to adjust. Both the North Central and the South regions show inelastic price elasticity of supply $(\mathrm{Pes}<1)$ (see Table IV). While the estimated result in the North Central region is 0.23 , it is 0.54 in the South region, a higher value (see Table IV).

Given the backdrop that maize is an economically important crop in the North Central region and its regional production accounts for $50 \%$ of the total maize production within the United States, responses of farmers to changes in price in this region are not aggressive in the short-term. Still, an increase in maize price could slightly increase maize supply (see Table IV). In contrast, in the South region, average annual revenue is comparatively lower. An increase in maize price within the short-term is considered to link an increase in revenue. The relatively lower annual revenue in this region makes farmers more sensitive and reactive to changes in maize prices than the North Central area.

TABLE IV: Price Elasticity of MAIZE SUPPLY IN THE NORTH CENTRAL AND THE SOUTH REGIONS IN THREE DIFFERENT SCENARIOS

\begin{tabular}{l|ll}
\multicolumn{2}{c}{ AND THE SOUTH REGIONS IN THREE DIFFERENT SCENARIOS } \\
\hline \hline \multirow{2}{*}{ Scenario } & Price elasticity of maize supply \\
\cline { 2 - 3 } $\begin{array}{l}\text { Short-term, (Variables } A, M A, L \text { are } \\
\text { fixed, and } C F \text { is adjustable) }\end{array}$ & 0.23 & 0.54 \\
\hline $\begin{array}{l}\text { Medium-term, (Variables } A \text { and } M A \\
\text { are fixed, } C F \text { and } L \text { are adjustable) }\end{array}$ & 1 & 0.86 \\
\hline $\begin{array}{l}\text { Long-term, (Variable } A \text { is fixed, } C F, L \\
\text { and } M A \text { are adjustable) }\end{array}$ & 3.02 & 2.09 \\
\hline \hline
\end{tabular}

In the medium-term, land use variable $A$ and agricultural machinery use variable $M A$ are fixed. Labor variable $L$ and applied chemical fertilizer variable $C F$ are allowed to adjust. Price elasticity of maize supply increases in both regions. These phenomena could be attributed to the stimulating effects of flexible changes in labor and chemical fertilizer. While the estimated result in the North Central region is 1 , it is 0.86 in the South region (see Table IV).

In the long-term, land use variable $A$ is fixed. Labor variable $L$, applied chemical fertilizer variable $C F$ and agricultural machinery use variable $M A$ are allowed to adjust. Both the North Central and the South regions show elastic price elasticity of supply (Pes $>1$ ). While the estimated result in the North Central region is 3.02, it is 2.09 in the South region (see Table IV).

When more variables become adjustable in the longer time span, management flexibility of input adjustment increases. Given the background that farmers in the North Central region highly relies on maize production to support their family, the increased management flexibility of input adjustment allows farmers to apply optimal inputs to increase maize supply, leading to more sensitive responses to changes in prices. Thus, the North Central show higher values of price elasticity of supply for the medium-term scenario and the long-term scenario.

TABLE V: APPlied CHEMICAL FERTILIZER PRICE Elasticity of MAIZE SuPPly IN THE NORTH CENTRAL AND THE SOUTH REGIONS IN THREE DIFFERENT SCENARIOS

\begin{tabular}{l|lc}
\hline \hline \multirow{2}{*}{ Scenario } & \multicolumn{2}{|l}{$\begin{array}{l}\text { Applied chemical fertilizer price } \\
\text { elasticity of maize supply }\end{array}$} \\
\cline { 2 - 3 } & North Central & South \\
\hline $\begin{array}{l}\text { Short-term, (Variables } A, M A, L \text { are } \\
\text { fixed, and } C F \text { is adjustable) }\end{array}$ & -0.22 & -0.54 \\
\hline $\begin{array}{l}\text { Medium-term, (Variables } A \text { and } M A \\
\text { are fixed, } C F \text { and } L \text { are adjustable) }\end{array}$ & -0.36 & -0.66 \\
\hline $\begin{array}{l}\text { Long-term, (Variable } A \text { is fixed, } C F, \\
L \text { and } M A \text { are adjustable) }\end{array}$ & -0.73 & -1.09 \\
\hline \hline
\end{tabular}

Next to the maize price elasticity of supply, applied chemical fertilizer price elasticity of maize supply is examined (see Table V). When more variables become 
adjustable in the longer time span, the impacts of applied chemical fertilizer costs on maize supply increase in both the North Central and the South regions. In all scenarios, the estimated results indicate that an increase in applied chemical fertilizer cost decreases maize supply in both the regions. Given the background that the soil nutrient contents and qualities in the South, a region growing high volumes of tobacco and cotton in former years, are not as high as the North Central region, more chemical fertilizer might be required, which in turn influences the costs. In fact, in all scenarios, South region appears to be more sensitive to cost changes in applied chemical fertilizer.

TABLE VI: LABOR PRICE ElASTICITY OF MAIZE SUPPLY IN THE NORTH CENTRAL AND THE SOUTH REgIONS IN Two DIFFERENT SCENARIOS

\begin{tabular}{l|ll}
\hline \hline \multirow{2}{*}{ Scenario } & \multicolumn{2}{|c}{ Labor price elasticity of maize supply } \\
\cline { 2 - 3 } & North Central & South \\
\hline $\begin{array}{l}\text { Medium-term, (Variables } A \\
\text { and } M A \text { are fixed, } L \text { and } C F \text { are } \\
\text { adjustable) }\end{array}$ & -0.64 & -0.21 \\
\hline $\begin{array}{l}\text { Long-term, (Variable } A \text { is } \\
\text { fixed, and } L, C F, \text { and } M A \text { are } \\
\text { adjustable) }\end{array}$ & -1.28 & -0.34 \\
\hline \hline
\end{tabular}

Labor price elasticity of maize supply in both regions is also examined (see Table VI). In the short-term, labor variable $L$ is fixed and only the chemical fertilizer $C F$ is adjustable. Thus, labor price elasticity of supply is not examined in the short-term scenario. In the medium-term, both regions show inelastic price elasticity of supply $(\mathrm{Pes}<1)$ $(-0.64$ in the North Central region and -0.21 in the South region) (see Table VI). In the long-term scenario, the response of maize production to changes in labor cost increases. The North Central region is -1.28 and the South region is -0.34 (Table VI). The results indicate an increase in agricultural labor cost decreases maize supply in both regions. For all types of agricultural production, labor is a key input element over the production process. A further increase in labor cost could decrease the efficiency of maize production, which in turn affects the final output. The South region, in contrast, has lower annual revenue. Furthermore, more agriculture population is available. Thus, the impacts of cost increase in labor on maize output are comparatively smaller.

TABLE VII: AgRiCUltural MACHINERY USE PRICE ElASTICITY OF MAIZE SUPPLY IN THE NORTH CENTRAL AND THE SOUTH REGIONS IN THE LONG-TERM SCENARIO

\begin{tabular}{l|lc}
\hline \multirow{2}{*}{ Scenario } & $\begin{array}{l}\text { Agricultural machinery use price } \\
\text { elasticity of maize supply }\end{array}$ \\
\cline { 2 - 3 } & North Central South \\
\hline $\begin{array}{l}\text { Long-term, (Variable } A \text { is fixed, } \\
C F, L \text { and } M A \text { are adjustable) }\end{array}$ & -1.01 & -0.66 \\
\hline \hline
\end{tabular}

Since the agricultural machinery use variable $M A$ is set to be adjustable in the long-term scenario, agricultural machinery use price elasticity of maize supply in the long-term scenario in the North Central and the South regions is examined. While the estimated result in the North Central region is -1.01 , it is -0.66 in the South region (see Table VII). The estimated results indicate an increase in agricultural machinery cost decreases maize supply in both regions. In the North Central region, maize production scale is large. Agricultural machinery is widely and efficiently used among farmers compared to other regions. Thus, an increase in agricultural machinery cost could have a larger impact on the decision-making processes of farmers and the corresponding maize supply.

\section{DISCUSSION}

The estimated results indicate the South region in the short-term is more responsive to changes in maize prices than the North region, opposite from the results examined in the medium-term scenario and the long-term scenario. The results reflect the differences in regional economic condition and management awareness. Given the backdrop that the average annual revenue in the South is lower, farmers in the region are more reactive to changes in maize prices in the short-term. In the North Central region, maize production scale is large, even by American scale of farm production. When more variables fluctuate in the longer time span, input adjustment and management strategies become more flexible and agile, enabling farmers in this region to better adjust their input-output calculations corresponding to changes in prices and input costs. In all scenarios, impacts of labor costs and machinery costs on maize supply are larger in the North Central region, reflecting the importance of these variables to the region. In all scenarios, changes in chemical fertilizer costs have larger impacts on maize supply in the South region, reflecting the requirement of more nutrients to the soil in the region. The results are in line with the research findings found by Li and Suzuki [3].

\section{CONCLUSION}

This paper analyzes the impacts of price incentives, costs and management awareness on maize supply in the North Central and the South regions of the United States. The converted supply functions are used to analyze the reaction of farmers to the exterior environment under an optimized condition in each region. It has been found that differences in regional economic and environmental condition could have different impacts on the decision-making processes of farmers and maize supply.

Different regional agricultural policies rather than a standardized national agricultural policy that aim to maintain or increase the incentives of farmers to produce maize might be efficient. Such a strategy may be more efficient in addressing food security issues and stabilizing market price and supply of the crop, as well as adapting to the progress of climate change. All in all, further research should be conducted to ensure the long-term food security.

\section{REFERENCES}

[1] X. Li and C. McMillan, "Corporate strategy and the weather: Towards a corporate sustainability platform," Journal of Problems and Perspectives in Management, vol. 12, issue 2, pp. 200-214, 2014.

[2] X. Li, T. Takahashi, N. Suzuki, and H. M. Kaiser, "The impacts of climate change maize yields in the United States and China," Agricultural Systems, vol. 104, pp. 348-353, April 2011.

[3] X. Li and N. Suzuki, "Implications of climate change impacts on regional maize production in the United States: Risk mitigation strategies and food security," International Journal of Environmental Science and Development, vol. 4, pp. 446-451, October 2013. 
[4] USDA National Agricultural Statistics Service. (2015). Data and statistics quick stats. [Online]. Available: http://www.nass.usda.gov/Quick_Stats/Lite/

[5] S. Kane, J. Reilly, and R. Bucklin, "Implications of the greenhouse effects for world agricultural commodity markets," presented at the Western Economic Association Conference, Lake Tahoe, 1989.

[6] H. M. Kaiser, S. J. Riha, D. S. Wilks, D. G. Rossiter, and R. Sampath, "A farm-level analysis of economic and agronomic impacts of gradual climate warming," American Agricultural Economics Association, vol. 75, pp. 387-398, May 1993.

[7] R. Mendelsohn, W. D. Nordhaus, and D. Shaw, "The impact of global warming on agriculture: A ricardian analysis," The American Economic Review, vol. 84, pp. 753-771, September 1994.

[8] D. L. Phillips, J. J. Lee, and R. F. Dodson, "Sensitivity of the US corn belt to climate change and elevated $\mathrm{CO}_{2}$ : I. Corn and soybean yields," Agricultural Systems, vol. 52, pp. 481-502, December 1996.

[9] C. Rosenzweig, F. N. Tubiello, R. Goldberg, E. Mills, and J. Bloomfield, "Increased crop damage in the US from excess precipitation under climate change," Global Environmental Change, vol. 12, pp. 197-202, October 2002.

[10] G. Tan and R. Shibasaki, "Global estimation of crop productivity and the impacts of global warming by GIS and EPIC integration," Ecological Modelling, vol. 168, pp. 357-370, October 2003.

[11] C. C. Chen, B. A. McCarl, and D. E. Schimmelpfennig, "Yield variability as influenced by climate: a statistical investigation," Climate Change, vol. 66, pp. 239-261, September 2004.

[12] D. B. Lobell and M. B. Burke, "On the use of statistical models to predict crop yield responses to climate change," Agricultural and Forest Meteorology, vol. 150, pp. 1443-1452, July 2010.

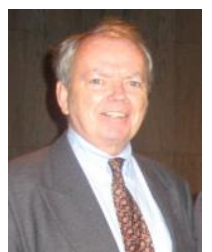

Charles J. McMillan is a professor of international business, York University, Toronto. He is the author of nine books and monographs related to international business and global management, including the Japanese Industrial System, published in English, Japanese, Malaysian and Russian editions, and The Strategic Challenge: From Surfdom to Surfing in the
Global Village. He has written and lectured extensively on globalization, bilateral and multilateral trade agreements, corporate governance, Japanese science and technology policy, and economic development. He has more than 80 technical articles and papers in such prestigious academic journals as McGill Law Review, Academy of Management Journal, Canadian Public Policy, Ivey Business Journal, California Management Review, Policy Options, Canadian Public Administration, Journal of Business Strategy, as well as in such publications as The New York Times, Nihon Keizai Shimbun, the Central Asia Post, The Globe and Mail, The National Post and The Toronto Star.

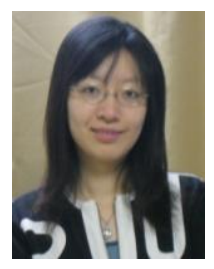

Xiang $\mathbf{L i}$ is an assistant professor at the Chiba University in Japan. She graduated from the University of British Columbia, Canada, with the degree of bachelor of science for Natural Resources Conservation in 2007. She received her science master degree in 2010 and Ph.D. degree in 2013 for International Environmental Economics at the University of Tokyo in Japan. She was a DBA director at the Graduate School of International Corporate Strategy of Hitotsubashi University, a national University in Japan. She worked as an assistant professor at the Academy for Co-creative Education of Environment and Energy Science of Tokyo Institute of Technology, another national University in Japan. Now, she works as an assistant professor at Chiba University, another national University in Japan, and now belongs to the faculty of Law, Politics \& Economics. Among Li's published refereed academic articles and issued patents, one that focused on agricultural production and climate change adaptation strategy has been highlighted and introduced by Nature Climate Change Journal (Nature Publishing Group) in February 2011. 